\title{
LIFE QUALITY IN CASES WITH CHRONICAL DEGENERA- TIVE ILLNESS OF LOCOMOTIVE SYSTEM REGARDING SEX, AGE AND OVERWEIGHT
}

\author{
Munevera Bećarević ${ }^{1}$ \\ Duška Bećirović \\ Sead Ćebić \\ Suad Sivić
}

Original scientific paper

Public Health institution in Banovici

Public Health institution in Zivinice,

Private ordination ,'Ćebići“"

Organization and health economy. Department of public health in Zenica/Doboj County, University of Zenica, faculty of health

Received: 24.08 .2012

UDC: $616.72-002.77$

Accepted: 03.09.2012

$616.7-036.22$

\begin{abstract}
Disturbances of muscle and skeleton system are related to pain, functional damages and inability to work. Measure of life quality offers a sequence of data on illness influence on everyday functioning. The aim of this paper is evaluation of life quality in cases with degenerative illnesses of locomotive system and influence of sex, age, weist and BMI on life quality.

Epidemiologic research was conducted on 71 tested subjects with diagnosis of chronical degenerative reumatical illness. Tested subject were measured weist values, BMI was determined and all of them fulfilled EQ5D questionnaire for life quality assessment. According to VAS scale their health condition was evaluated. Life quality of tested subjects was decreased especially in department of depression and increased concern (2.30 - 2.57) as well as pain and discomfort (2.11 - 2.31). We didn't determine statistically significant sex influence $(p>0,05)$, age, $(p>0,05)$ weist values $(p>0,05)$ or BMI $(p>0,05)$ our tested subjects life quality. According to VAS scale health condition of tested subjects is low $(6,76 \pm 1,04)$.
\end{abstract}

Key words: osteoarthritis, life quality, EQ 5D, BMI, overweight

\section{INTRODUCTION}

Degenerative joint illnesses (arthrosis, osteoarthrosis, osteoarthritis, OA) is noninflamatory joint illness characterized with primary dissolvment of cartilage that leads to disturbed joint functioning, secondary inflammatory changes, pain and ankhilosis (Vrhovac et al., 2007).
There are different ways of OA defining, therefore, certain studies use special questionnaires, radiological definitions of OA and symptomatic OA definitions that include joints pain and radiology proof of OA (Felson, 1998).

\footnotetext{
${ }^{1}$ Correspodence to:

Bećarević Munevera, Public Healt institution in Banovici, Bosnia and Herzegovina

Banovici, Bosnia and Herzegovina

Phone: 0038761282873

E-mail: b.munevera@gmail.com
} 
OA is significant public-health problem for its large influence on invalidity and joined morbidity in elderly person (Guccione et al., 1994, pp. 351-358), and increasment of OA frequency with prolonging of life time and larger involvement of older and overweight population in general population number in world is also expected. It is estimated (Lawrence and associates. 2008) that 26,9 million Americans suffer from certain type of OA in age from 25 and more. Study that included 10 year monitoring confirmed diagnosing of knee $\mathrm{OA}$ in 5,8\%, hip OA 7,3\% and arm OA 5,6\% and overweight was significantly related to knee and arm OA but not related to hip OA (Grotle, et al., 2008, p. 132).

Prevalence of cervical syndrome in Norway is 13 , $8 \%$, in Finland $9,5 \%$ in men and $13,5 \%$ in women, and America $7 \%$ in men and $9,45 \%$ in women (Kapidžić, 2007, pp. 117-122). Total prevalence of OA reported is $18 \%$ of Ontario population older than 16 and in $2,5 \%$ of population it results in long-term invalidity (Badley, 1995).

Economic influence of OA in terms of direct medical expense and as consequence of leaving work is impressive (Gabriel et al., 1997) and expenses of leaving work for joint ache are estimated as 3\% of total homemade production (Felson et al., 2000). In 2005 hospitalization expenses due to intervention on muscular and bone system in USA that generally included artroplastics and hip replacement were 31,5 billion dollars or more than $10 \%$ of total expenses' in all hospitals.

It emphasizes dramatically increase of social expenses' of OA because only 10 years earlier total OA expense in USA was estimated on 15,5 billion dollars (in the year 1994) (Yelin, 1998).

Concerning the fact that preventive interventions and therapeutic possibilities for OA are limited we can expect that morbidity and economic influence of OA increase with ageing of developed world population. Pathogenesis of OA is probably includes multiple factors and mutual influence of system risk factors such as overweight and older age with local risk factors such as mechanical overload and traumas can develop diagnosing of this illness in any joint (Chaganti \& Lane, 2011). Systematic factors that can lead to increased risk of OA under the influence of local factors such as injury can initiate cascade changes than can lead to development of OA. While systematic factors such as age and sex are general risk factors, local factors on the other hand can have potential for intervention and change of illness risk.

Several studies confirmed that older life age is related with increased frequency of OA (Oliveria et al., 1995). Overweight in adult can lead to changes in muscular and bone system that result with larger risk in overweight population for development of muscular and skeleton illnesses (Messier, Loeser \& Miller, 2004). It is also proven that associating of older age with increasment of BMI is related to increased incidence of hip OA (Murphy et al., 2008).

Framingham study has shown that incidence of knee OA diagnosing is 1,7 times higher in women than in men (Felson et al., 1995). It is estimated that life age increases risk of symptomatic knee OA up to $46,8 \%$ observed in women during menopause (Oliveria et al., 1995) what proves the fact that hormonal problems can contribute to development of OA.

Muscular and skeleton pain and OA are ranged from middle to long-term overweight consequences in adults. Data from many studies show strong relation between overweightness, defined as BMI (body mass index) above 30, x-ray knee OA, for example in Framingham study (Felson et al., 1995), John Hopkins precursor of study (Gelber et. al., 1999), joined study in Great Britain (Cooper et al., 2000) and Dutsch (Reijman et al., 2007). Two primary theories were suggested for explanation of relation of overweightness and OA: biomechanical and systematic/metabolic mechanism (Van Saase et al., 1988). Biomechanical theory suggests that overweightness increases axial pressure (local efficiency) with consequential degenerativity of joint cartilage. Metabolic theory considers that certain metabolic factors have negative influence on cartilage what results in risk increasment of $\mathrm{OA}$ by overweightness (Hartz et. al., 1986, pp. 311-319).

Literature data have shown that muscular mass or muscular strength protective factors for OA diagnosis development (Toda et al., 2000). 
Some data show that in $34 \%$ of women in middle life age that have OA on one side in two years time OA will develop in contra lateral knee, and overweight have significant influence on diagnosing of OA which is 5 times more often in overweight women than in those cases with lower BMI (Hartz, Hart \& Doyle, 1994, pp. 565-568). Datas from Chingford study show that overweight persons have almost 18 times increased risk for development of bilateral knee OA (Spector, 1990). Since overweightness relation with hip OA is less and noncinsistent it leads to conclusion that influence of overweightness on knee is not necessary of mechanical nature. Same results point to therapeutic weight loss potential (Cooper et al., 1992). The aims of this research were to evaluate life quality of our tested subjects with earlier diagnosis of degenerative reumatological disease based on EQ 5D questionnaire and to evaluate age, sex and overweightness (BMI and weist values) on life quality of tested subjects.

\section{TESTED SUBJECTS AND METHODS}

Epidemiological study in department of family medicine in institution for health in Banovici and Živinice was conducted in period from 30.1 i 10.2.2012. Research conducted all patients of both sexes with determined diagnose of chronic degenerative disease of locomotive system (coxarthreosis, gonarthrosis, cervical or lumbal ache syndrome) that visited these ordinations in this period. Research didn't include test subjects with recently diagnosis of degenerative illness. All tested subjects were taken data of age, sex, occupation, years of life, family status. All tested subjects also fulfilled EQ5D questionnaire on life quality that is used as standardized measuring instrument for life quality measuring concerning the health condition of tested subject (EQ 5D questionnaire follows). Questionnaire contains 5 questions related to mobility, ability to self-concern, conducting of usual activities, questions related to pain and concern/fear for ones health. Questionnaire contains 3 answers and answers are graded from 1 to 3,1 - absence of problem, and number increases with life quality decreasment.
EQ-5D questionnaire

Mobility

1. I have no problem with mobility

2. I have certain problems with mobility

3. I am strapped to bed

Self - concerning

1. I have no problem with self-concerning

2. I have certain problems during self- washing and dressing

3. I am not in condition to wash and dress Usual activities (ex. Job, studying, house jobs, family or free activities)

1. I have no problem with conducting of usual activities

2. I have certain problems in conducting of my usual activities

3. I am in no condition to perform my usual activities

Pain/discomfort

1.I feel no pain or discomfort

2.I feel certain pain and discomfort

3.I feel ultimate pain and discomfort

Concern/depression

1.I am not concerned or sad

2.I am relatively concerned or sad

3.I am totally concerned or sad

All patients were offered a analogue-visual scale (VAS) (Wewers i Lowe 1990) on which tested subjects graded degree of suffering (pain) from 1 to 10. VAS scales' length is 10 units, from 0 to 10 on which between mark 0 stands for no pain and 10 stands for the most possible pain, you can show what kind of pain you're dealing with. Their height values are also taken, as well as weight, weist values and BMI index value is determined. According BMI values tested subjects were divided into those with normal weight values (BMI index up to $25 \mathrm{~kg}$ / $\mathrm{m} 2$ ) and overweight, and according to weist values (women $\leq 88 \mathrm{~cm}$, men $\leq 102 \mathrm{~cm}$ ) and group with weist above referent values. Based on received data, life quality is determined through EQ 5D questionnaire. Sex, age, overweight and weist values influence on life quality of tested subjects is also determined. Statistical data were processed in SPSS 16 computer programme. 
Scientific methods of descriptive statistics (frequency, arithmetical values, standard error and standard deviation) were used in analysis and life quality differences analysis used x2 and Pearsons correlation for certain groups. Statistical significance method for values "p", ussual level of signifficance " $p<0,05$ " was selected.

\section{RESULTS}

71 tested subject was included in our research, $36(50$, $7 \%$ ) of men in average life age of 47, 22 years and 35 $(49,3 \%)$ of women in average life 58,56 years. Statistically significant difference in age structure between sexes was also evident. 32, $4 \%$ of tested subjects were housewives, 25, 4\% were with secondary education level, $23,9 \%$ were highly qualified workers, $12,7 \%$ were low qualification workers and $5,6 \%$ were retired. $81,7 \%$ lives with their families, $11,3 \%$ lives with their children and 7, 0\% lives single life.

Lumbal ache syndrome was evident in 45 (63, 33\%), cervical syndrome in $11(15,49 \%)$ and gonarthrosis in $15(21,12 \%)$ tested subjects. Average time of disease period was $8,06 \pm 6,13$ years. According to our results life quality of our tested subjects is lower for 1-1, 5 degrees according EQ5D questionnaire. Decreasment of life quality is most evident in area of concern and depression (2.30-2.57), pain and discomfort (2.11-2.31) and usual activities (1.94-2.17). Smaller decreasment of life quality is evident in mobility $(1.76-1.93)$, and less evident in self-concern $(1.50-1.74)$ (Table $1,3 \mathrm{i}$ 4). Our research has shown the absence of statistically significant differences according to age (table 1) or in one parameter EQ-5D questionnaire on life quality: in problems with locomotion $(\mathrm{X} 2(1)=0,144 ; \mathrm{p}>0,05)$, in ability of self-concern $(X 2(1)=0,410 ; p>0,05)$, in ability to perform usual activities $(\mathrm{X} 2(2)=0,404 ; \mathrm{p}$ $>0,05)$, in feeling of discomfort or pain $(\mathrm{X} 2(1)=0,872$; $\mathrm{p}>0,05)$. According to VAS scale degree of health condition in our tested subjects is $(6,76 \pm 1,04)$.

Table 1. Gender influence on life quality in cases with degenerative illnesses of locomotive system

\begin{tabular}{|c|c|c|c|c|}
\hline & \multirow{3}{*}{ Sex } & \multicolumn{3}{|r|}{$95 \%$ Confidence interval for } \\
\hline & & & Std. & Std. Error of Mean \\
\hline & & Mean & Deviation & Mean \\
\hline \multirow{3}{*}{$\begin{array}{l}\text { EQ-5D } \\
\text { mobility }\end{array}$} & male & 1.86 & 0.351 & $1.74-1.98$ \\
\hline & female & 1.83 & 0.382 & $1.70-1.96$ \\
\hline & Total & 1.85 & 0.364 & $1.76-1.93$ \\
\hline \multirow{3}{*}{$\begin{array}{l}\text { EQ-5D } \\
\text { Self- care }\end{array}$} & male & 1.58 & 0.500 & $1.41-1.75$ \\
\hline & female & 1.66 & 0.482 & $1.49-1.82$ \\
\hline & Total & 1.62 & 0.489 & $1.50-1.74$ \\
\hline \multirow{3}{*}{$\begin{array}{l}\text { EQ-5D } \\
\text { Usual } \\
\text { activities }\end{array}$} & male & 2.08 & 0.500 & $1.91-2.25$ \\
\hline & female & 2.03 & 0.453 & $1.87-2.18$ \\
\hline & Total & 2.06 & 0.475 & $1.94-2.17$ \\
\hline \multirow{3}{*}{$\begin{array}{l}\text { EQ-5D } \\
\text { Pain/discomfo } \\
\text { rt }\end{array}$} & male & 2.17 & 0.378 & $2.04-2.29$ \\
\hline & female & 2.26 & 0.443 & $2.10-2.41$ \\
\hline & Total & 2.21 & 0.411 & $2.11-2.31$ \\
\hline \multirow{3}{*}{$\begin{array}{l}\text { EQ-5D } \\
\text { Anxiety } \\
\text { /depression }\end{array}$} & male & 2.47 & 0.560 & $2.28-2.66$ \\
\hline & female & 2.40 & 0.604 & $2.19-2.61$ \\
\hline & Total & 2.44 & 0.579 & $2.30-2.57$ \\
\hline
\end{tabular}

In this research age didn't significantly influence on life quality of tested subjects (table 2). 
Table 2. Age influence on life quality in cases with degenerative illnesses of locomotive system

\begin{tabular}{|c|c|c|c|c|c|c|}
\hline \multicolumn{2}{|l|}{ EQ } & \multirow{3}{*}{$\begin{array}{l}\text { EQ-5D } \\
\text { mobility }\end{array}$} & \multirow[b]{2}{*}{ EQ-5D } & \multicolumn{2}{|r|}{ EQ-5D } & \multirow[b]{2}{*}{ EQ-5D } \\
\hline $5 \mathrm{D}$ & & & & & Pain/discomf & \\
\hline & & & \multicolumn{3}{|c|}{ Self- care Usual activities ort } & Anxiety/depression \\
\hline & $\begin{array}{l}\text { Pearson } \\
\text { Correlation }\end{array}$ & 0.022 & -0.098 & -0.110 & 0.012 & 0.048 \\
\hline & Sig. (2-tailed) & 0.857 & 0.418 & 0.361 & 0.919 & 0.694 \\
\hline$\stackrel{8}{<} 1$ & $\mathrm{~N}$ & 71 & 71 & 71 & 71 & 71 \\
\hline
\end{tabular}

According to Pearsons' correlation of BMI (table 4) and weist values (table 3) didn't significantly influence on life quality in cases with degenerative illnesses of locomotive system, what Pearsons' correlation has proven (table 5).

Table 3. Weist values influence on life quality in cases with degenerative illnesses of locomotive system.

\begin{tabular}{|c|c|c|c|c|c|}
\hline & Weist & Mea & Std. & Std. E & 95\% Confidence interval for \\
\hline & values & $\mathrm{n}$ & Deviation & Mean & Mean \\
\hline \multirow{3}{*}{$\begin{array}{l}\text { EQ-5D } \\
\text { mobility }\end{array}$} & normal & 1.85 & 0.364 & 0.063 & $1.72-1.98$ \\
\hline & $\begin{array}{l}\text { Above } \\
\text { normal }\end{array}$ & 1.84 & 0.370 & 0.060 & $1.72-1.96$ \\
\hline & Total & 1.85 & 0.364 & 0.043 & $1.76-1.93$ \\
\hline \multirow{3}{*}{$\begin{array}{l}\text { EQ-5D } \\
\text { Self- care }\end{array}$} & normal & 1.64 & 0.489 & 0.085 & $1.46-1.81$ \\
\hline & $\begin{array}{l}\text { Above } \\
\text { normal }\end{array}$ & 1.61 & 0.495 & 0.080 & $1.44-1.77$ \\
\hline & Total & 1.62 & 0.489 & 0.058 & $1.50-1.74$ \\
\hline \multirow{3}{*}{$\begin{array}{l}\text { EQ-5D } \\
\text { Usual } \\
\text { activities }\end{array}$} & normal & 2.06 & 0.496 & 0.086 & $1.88-2.24$ \\
\hline & $\begin{array}{l}\text { Above } \\
\text { normal }\end{array}$ & 2.05 & 0.462 & 0.075 & $1.90-2.20$ \\
\hline & Total & 2.06 & 0.475 & 0.056 & $1.94-2.17$ \\
\hline \multirow{3}{*}{$\begin{array}{l}\text { EQ-5D } \\
\text { Pain/ } \\
\text { discomfort }\end{array}$} & normal & 2.15 & 0.364 & 0.063 & $2.02-2.28$ \\
\hline & $\begin{array}{l}\text { Above } \\
\text { normal }\end{array}$ & 2.26 & 0.446 & 0.072 & $2.12-2.41$ \\
\hline & Total & 2.21 & 0.411 & 0.049 & $2.11-2.31$ \\
\hline \multirow{3}{*}{$\begin{array}{l}\text { EQ-5D } \\
\text { Anxiety } \\
\text { /depression }\end{array}$} & normal & 2.45 & 0.564 & 0.098 & $2.25-2.62$ \\
\hline & $\begin{array}{l}\text { Above } \\
\text { normal }\end{array}$ & 2.42 & 0.599 & 0.097 & $2.22-2-62$ \\
\hline & Total & 2.44 & 0.579 & 0.069 & $2.30-2.57$ \\
\hline
\end{tabular}


Table 4. BMI influence on life quality in cases with degenerative illnesses of locomotive system

\begin{tabular}{|c|c|c|c|c|c|}
\hline & \multirow{3}{*}{$\begin{array}{l}\text { BMI } \\
\text { categories }\end{array}$} & \multirow[b]{3}{*}{ Mean } & \multicolumn{2}{|l|}{ Std. } & \multirow[t]{3}{*}{$95 \%$ Confidence interval } \\
\hline & & & Deviatio & Std. Error & \\
\hline & & & $\mathrm{n}$ & Mean & \\
\hline \multirow{4}{*}{ mobility } & normal & 1.82 & 0.393 & 0.095 & $1.62-2.03$ \\
\hline & overweigh & & & & $1.75-1.95$ \\
\hline & $\mathrm{t}$ & & & & \\
\hline & Total & 1.85 & 0.364 & 0.043 & $1.76-1.93$ \\
\hline \multirow{4}{*}{$\begin{array}{l}\text { EQ-5D } \\
\text { Self- care }\end{array}$} & normal & 1.53 & 0.514 & 0.125 & $1.26-1.79$ \\
\hline & overweigh & & & & $1.52-1.78$ \\
\hline & $\mathrm{t}$ & 1.03 & 0.402 & 0.000 & \\
\hline & Total & 1.62 & 0.489 & 0.058 & $1.50-1.74$ \\
\hline \multirow{3}{*}{$\begin{array}{l}\text { EQ-5D } \\
\text { Usual }\end{array}$} & normal & 1.88 & 0.485 & 0.118 & $1.63-2.13$ \\
\hline & overweigh & & & & $1.98-2.24$ \\
\hline & $\mathrm{t}$ & 2.11 & 0.462 & 0.063 & \\
\hline activities & Total & 2.06 & 0.475 & 0.056 & $1.94-2.17$ \\
\hline \multirow{4}{*}{$\begin{array}{l}\text { EQ-5D } \\
\text { Pain/ } \\
\text { discomfort }\end{array}$} & normal & 2.12 & 0.332 & 0.081 & $1.95-2.29$ \\
\hline & overweigh & 224 & 0432 & $0,0<0$ & $2.12-2.36$ \\
\hline & $\mathrm{t}$ & & & & \\
\hline & Total & 2.21 & 0.411 & 0.049 & $2.11-2.31$ \\
\hline \multirow{4}{*}{$\begin{array}{l}\text { EQ } \\
\text { Anxiety } \\
\text { /depression }\end{array}$} & $-5 \mathrm{D}$ normal & 2.29 & 0.686 & 0.166 & $1.94-2.65$ \\
\hline & overweigh & & & & $2.33-2.63$ \\
\hline & $\mathrm{t}$ & 2.40 & 0.540 & 0.074 & \\
\hline & Total & 2.44 & 0.579 & 0.069 & $2.30-2.57$ \\
\hline
\end{tabular}


Table 5. Weist values and BMI influence on life quality in cases with degenerative illnesses of locomotive system.

\begin{tabular}{|c|c|c|c|c|c|c|}
\hline & & & & & EQ-5D & \\
\hline EQ & & EQ-5D & EQ-5D & Usual & Pain/discomfor & EQ-5D \\
\hline $5 \mathrm{D}$ & & mobility & Self- care & activities & $\mathrm{t}$ & Anxiety/depression \\
\hline \multirow[t]{3}{*}{ OS } & $\begin{array}{l}\text { Pearson } \\
\text { Correlation }\end{array}$ & 0.092 & -0.122 & -0.147 & 0.098 & 0.027 \\
\hline & $\begin{array}{l}\text { Sig. } \\
\text { tailed) }\end{array}$ & 0.443 & 0.309 & 0.222 & 0.415 & 0.824 \\
\hline & $\mathrm{N}$ & 71 & 71 & 71 & 71 & 71 \\
\hline \multirow[t]{3}{*}{ BMI } & $\begin{array}{l}\text { Pearson } \\
\text { Correlation }\end{array}$ & 0.142 & 0.047 & -0.020 & 0.094 & 0.086 \\
\hline & $\begin{array}{l}\text { Sig. } \\
\text { tailed) }\end{array}$ & 0.237 & 0.695 & 0.865 & 0.436 & 0.476 \\
\hline & $\mathrm{N}$ & 71 & 71 & 71 & 71 & 71 \\
\hline
\end{tabular}

\section{DISCUSSION}

Generally, measure of life quality can offer a sequence of data on influence of rheumatic and other illnesses on everyday functioning (Walker \& Littlejohn, 2007). Muscular - skeleton disturbances are often related with pain, functional damages and inability to work and are most often reasons for using of health resources (Verbrugge \& Juarez, 2006; Ang et al., 2005). Factors that influence on life quality in those with muscular-skeleton illnesses include not only pain and exhaustion but also difficulties in everyday activities starting from basic functions to more complicated tasks such job activities, raising of children etc. (Walker \& Littlejohn, 2007). Earlier research have shown significant decrease of life quality in those with rheumatic acute and chronical diagnosis (Lapčević et al., 2010).

Referent values for self-concerning section was from 1,40 to 1,47 in conducted research, where decrease of life quality was the least, in concerning and depression section 1,79-1,86 and for pain and and discomfort section 1,99-2,02 where the quality of life was the lowest (Lapčević et al., 2010). In this research life quality of tested subjects was lower, in self concerning section was from 1, 50-1, 74, where decreasment of life quality was the lowest, in pain and discomfort section from 2.11 to 2.31, and according to our research the most significant decreasment of life quality was in section for concerness and depression $2.30-2.57$. The existence of widely spread influence of rheumatic and other chronical illnesses on physical, psychological and social factors of those with these diagnoses is evident and during measuring of life quality the tool that covers more aspects of life qualities should be used. The one used in this research paper is compatible with earlier facts that show frequency of depressive symptoms in $60 \%$ of those with chronical somatic illness and that depression is related to bad results of healing as well as increased morbidity and mortality in rheumatic cases. 
Rheumatoid arthritis and fibromyalgia are related to changes in psychological functioning with 20 to $60 \%$ depressive symptoms (McWilliams et al., 2003). This research has also proven that the most evident decreasment of life quality was in section of concern and depression.

Some clinical and epidemiological studies have shown that patients with acute rheumatic diseases have lower life quality regarding healthy population (Salaffi et al., 2009), and concerning patients with chronical rheumatic illness (Wollfe \& Hawley, 1997). Osteoarthritis (OA) is important cause of long-term health problems and most usual reason for long-term invalidity in population. Long-term disability is followed by significant influence on everyday life including problems with immobility, dependability on others and difficulties in everyday activities, social isolation, decreasment of activities, employment and low payment (Badley, 1995). Knee $\mathrm{OA}$ is chronical condition that characterizes the loss of mutual function and persistent pain that reduces life quality (Dominick et al., 2004). The effectiveness of symptomatic knee OA on life quality is similar to those in breast cancer metastasis (Loyd et al., 2006). Studies in which VAS scale was used, graded from 0-100, have shown that average grade of health condition in America was 63 (Wollfe \& Hawley, 1997), and in Serbia 53, 75 (Lapčević et al., 2010). Average value of VAS scale in our research (graded from $0-10$ ) is $6,76 \pm 1,04$, which means that health status of our tested subjects is on lower level i.e. low level what is compatible to decreasment of quality life which is most evident in section of pain and discomfort.

Overweight and knee OA are among most frequent illnesses in Americans from 50 to 84 years of life (Dillon et al., 2006). A certain study determined that overweightness is related to bad life quality and that joint ache in overweight persons influence relation between BMI and life quality (Heo, et al., 2003, pp. 209-16). In overweight cases life quality is decreased for $12 \%$ in all age groups. Persons with knee osteoarthritis have quality of life decreased for $13 \%$ as well as in those with age of 50 and for $10 \%$ in those with 70 years of life and more (Losina et al., 2011). Some researches have shown that body mass as well as distribution of grease tissue is in- dependently related with knee OA (Abbate et al., 2006). Sanghi and associates confirmed theory that BMI and other anthropometrical measures have significant value with knee OA, but, in confrontation to general knowledge, peripheral grease in men and central grease in women (weist/hips measurement) are strongly related with knee OA than BMI (Sanghi et al., 2011). Our research has shown that weist values have no influence on life quality change in cases with degenerative illnesses of locomotive system. Also, there was no evident difference in evaluation of health status of tested subjects (according to VAS scale( with increased weist values regarding those with recommended weist values around $(6,7)$.

Study conducted in Finland on 823 tested subjects reported of strong connection of knee OA and BMI $=25-29,9$ or $>30,0$ (Toivanen et al.,2010). Similar results were found in Framingham study where 598 tested subjects without knee OA didn't have increased risk of developing the same diagnosis with increasment of BMI (Felson et al., 1995).

These results are important because of its consistency in analysis that overweight cases have risk of knee OA development and point to potential changeable risk factors when this illness is discussed with patients. OA is important cause to long-term health problems and are the most frequent reason for longterm invalidity in population. Long-term disability followed by significant influence on everyday life including problems with locomotion, dependability and trouble in everyday activities, social isolation, decreasment of activity, employment and low payment (Badley, 1995). If overweight cases could decrease body weight for 5 kilograms or if BMI could be in range of recommended values, $24 \%$ of surgical interventions on knee caused by OA would be avoided (Coggon et al., 2001). According to Messier, weight loss of 5\% during workout and healthy food programme improves function and mobility and decreases pain in overweight cases with OA (Messier et al., 2005).

However, each pound $(0,454 \mathrm{~kg})$ of weight loss will result with 4 times smaller pressure on knees during everyday activities, and if we observe this fact accumulated in thousands of steps on daily basis, this will result with clinical significance (Messier et al., 2005). 
According to results of this research, BMI has no influence on life quality change in cases with degenerative illnesses of locomotive system. Also, there is no significant difference in evaluation of health status of tested subjects (according to VAS scale) with increased weist values in comparing to those with recommended weist value (about 6,69- 6,77).

In older individuals with OA and RA generally lower health condition, physical condition, mental condition, sleeping and limitation of other activities is evident in comparing to those without arthritis (Dominick et al., 2004).

There are differences in life quality according to demographic markers and co $\neg$ morbidity among tested subjects with OA and RA (Dominick et al., 2004).

Other research have proven influence of older life age, race, life in shelters for old people, lower social status and more evident comorbidity with worse result of tests on life quality (Zhang et al., 2008; Wang \& Beydoun, 2007). Earlier research has proven that age has statistically significant influence on life quality in cases with chronic rheumatic illnesses that is evident in all 5 markers of life quality according to EQ 5D questionnaire (Lapčević et al., 2010). According to this research age doesn't have significant influence on life quality of tested subjects. In comparing to other researches (Wang \& Beydoun, 2007), in some researches men have lower quality of mental and physical health in comparing to women (Dominick et al., 2004). Newer approaches on invalidity research confirm the role of demographic, physical, psychological, social and environment factors that lead to worse outcome of chronical somatic conditions (Verbrugge \& Juarez 2006). It is proven that there is no evidence of statistically significant difference among sexes in any of EQ 5D questionnaire parameters. Even though our research haven't proven the influence of overweightness on life quality of our tested subjects, we shouldn't forget the proven fact that prevention of overweightness in 10 years time could prevent 178071 cases of coronary diseases, 889872 cases of diabetes mellitus and 111206 cases of surgical knee replacement (Losina et al., 2011). This decreasment of overweightness would prolong life age for 7,812 years and improve life quality in adult Americans in age of 50 to 84 years (Losina et al., 2011).

\section{CONCLUSION}

Our study has shown that life quality of cases with degenerative illnesses of locomotive system significantly decreased in all segments, especially in section of pain and discomfort and concern and depression. According to our results, age, sex and overweightness measured by weist values and BMI didn't show significant statistical influence on life quality of our testers. According to VAS scale, the level of health condition (pain) is on low level in our tested subjects.

\section{REFERENCE}

Abbate, LM., Stevens, J., Schwartz, TA., Renner, JB., Helmick, CG. and Jordan, JM. (2006). Anthropometric Measures, Body Composition, Body Fat Distribution, and Knee Osteoarthritis in Women. Obesity 14:1274-1281.

Ang, DC., Choi, H., Kroenke, K. and Wolfe, F. (2005). Comorbid depression is an independent risk factor for mortality in patients with rheumatoid arthritis. J Rheum 32:1013-1019.

Badley, EM. (1995). The effect of osteoarthritis on disability and health care use in Canada. J Rheumatol Suppl 43:19-22.

Chaganti, R K. and Lane NE. (2011). Risk factors for incident osteoarthritis of the hip and knee. Curr Rev Musculoskelet Med 4(3): 99-104.

Coggon, D., Reading, I., Croft, P., Mclaren, M., Barrett, D. and Cooper, C. (2001). Knee osteoarthritis and obesity. Int J Obes Relat Metab Disord 25(5):622-627.

Cooper, C., Cushnaghan, J., Kirwan, JR., Dieppe, PA., Rogers, J. and Mcalindon, T. (1992). Radiographic assessment of the knee joint in osteoarthritis. Ann Rheum Dis 51(1):80-82.

Cooper, C., Snow, S., Mcalindon, TE., Kellingray, S., Stuart, B. and Coggon, D. (2000). Risk factors for the incidence and progression of radiographic knee osteoarthritis. Arthritis Rheum 43:995-1000.

Dillon, CF., Rasch, EK., GU, Q. and Hirsch, R. (2006). Prevalence of knee osteoarthritis in the United States: arthritis data from the Third National Health and Nutrition Examination Survey 1991-94. J Rheumatol. 33:2271-2279.

Dominick, KL., Ahern, FM., Gold, CH. and Heller DA. (2004). Health-related quality of life among older adults with arthritis. Health Qual Life Outcomes 2:5.

Felson, DT., Zhang, Y., Hannan, MT., Naimark, A., Weissman, BN., Aliabadi, P. et al. (1995). The incidence and natural history of knee osteoarthritis in the elderly. The Framingham Osteoarthritis Study. Arthritis Rheum 38(10):1500-1505.

Felson, DT. and Zhang Y. (1998). An update on the epidemiology of knee and hip osteoarthritis with a view to prevention. Arthritis Rheum 41 (8):1343-1355.

Felson, DT., Lawrence, RC., Dieppe, PA., Hirsch, R., Helmick, CG., Jordan, et al. (2000). Osteoarthritis: new insights. Part 1: the disease and its risk factors. Ann Intern Med 133(8):635-646. 
Gabriel, SE., Crowson, CS., Campion, ME. and O'fallon, WM. (1997). Direct medical costs unique to people with arthritis. $J$ Rheumatol 24:719-725. Gelber, AC., Hochberg, MC., Mead, LA., Wang, NY., Wigley, FM. and Klag, MJ. (1999). Body mass index in young men and the risk of subsequent knee and hip osteoarthritis. Am J Med 107:542-548.

Grotle, M., Hagen, BK., Natvig, B., Dahl, AF. and Kvien, KT. (2008). Obesity and osteoarthritis in knee, hip and/or hand: An epidemiological study in the general population with 10 years follow-up. BMC Musculoskelet Disord 9.

Guccione, AA., Felson, DT., Anderson, JJ., Anthony, JM., Zhang, Y., Wilson, PW. Et Al. (1994). The effects of specific medical conditions on the functional limitations of elders in the Framingham Study. Am J Public Health 84(3).

Hartz, AJ., Fischer, ME., Bril, G., Kelber, S., Rupley, D, JR., Oken, B., et al. (1986). The association of obesity with joint pain and osteoarthritis in the HANES data. J Chronic Dis 39.

Hartz, TD., Hart, DJ., Doyle, DV. (1994). Incidence and progression of osteoarthritis in women with unilateral knee disease in the general population: the effect of obesity. Ann Rheum Dis 53.

Heo, M., Allison, DB., Faith, MS., Zhu, S. and Fontaine, KR. (2003). Obesity and quality of life: mediating effects of pain and comorbidities. Obes Res 11.

Walker, J.G. and Littlejohn, G.O. (2007). Measuring quality of life in rheumatic conditions. Clin Rheumatol 26:671-673.

Kapidžić-Bašić, N. (2007). Najčešće reumatske bolesti [Most rheumatic diseases]. B\&H, Tuzla: COPYGRAF.

Lapčević, M., Prvanova, D. and Đorđević S. (2010). Procena kvaliteta života obolelih od hronočni reumatskoh obolenja. Opšta medicina 16(3-4)113123).

Lawrence, RC., Felson, DT., Helmick, CG., Arnold, LM., Choi H, Deyo RA et al. (2008). National Arthritis Data Work-group: Estimates of the prevalence of arthritis and other rheumatic conditions in the United States. Part II. Arthritis Rheum 58:26-35. Lloyd, A., Nafees, B., Narewska, J., Dewilde, S. and Watkins, J. (2006) Health state utilities for metastatic breast cancer. Br J Cancer 95:683-690.
Losina, E., Walensky, RP., Reichmann, WM., Holt, HL., Gerlovin, H., Solomon, DH. et all. (2011) Impact of obesity and knee osteoarthritis on morbidity and mortality in older Americans. Ann Intern Med 154(4):217-26.

McWilliams, LA., Cox, BJ. and Enns MW. (2003) Mood and anxiety disorders associated with chronic pain: an examination in a nationally representative sample. Pain 106:127-133.

Messier, SP., Gutekunst, DJ., Davis, C. and DeVita, P. (2005). Weight loss reduces knee-joint loads in overweight and obese older adults with knee osteoarthritis. Arthritis and Rheumatism 52 (7) 2026 2032.

Messier, SP., Loeser, RF. and Miller, GD. (2004). Exercise and dietary weight loss in overweight and obese older adults with knee osteoarthritis: the arthritis, diet, and activity promotion trial. Arthritis and Rheumatism 50(5):1501-1510.

Murphy, L., Schwartz, TA., Helmick, CG., Renner, JB., Tudor, G., Koch, G. et all.(2008) Lifetime risk of symptomatic knee osteoarthritis. Arthritis Rheum 59(9):1207-1213.

Oliveria, SA., Felson, DT., Reed, JI., Cirillo, PA. and Walker, AM. (1995). Incidence of symptomatic hand, hip, and knee osteoarthritis among patients in a health maintenance organization. Arthritis Rheum 38(8):1134-1141.

Reijman, M., Pols, HA., Bergink, AP., Hazes, JM., Belo, JN. and Lievense AM. (2007). Body mass index associated with onset and progression of osteoarthritis of the knee but not of the hip. The Rotterdam Study. Ann Rheum Dis 66:158-162.

Salaffi, F., Carotti, M., Gasparini, S. and Intorcia, M. (2009). The health-related quality of life in rheumatoid arthritis, ankylosing spondylitis, and psoriatic arthritis: a comparison with a selected sample of healthy people. Health and Quality of Life Outcomes 7:25.

Sanghi, D., Srivastava, NR., Singh, A., Kumari, R., Mishra, R. and Mishra, A. (2011). The association of anthropometric measures and osteoarthritis knee in non-obese subjects: a cross sectional study. Clinics (Sao Paulo) 66(2): 275-279.

Spector, TD. (1990). The fat on the joint: osteoarthritis and obesity. J Rheumatol 17(3):283-284. 
Toda, Y., Segal, N., Toda, T., Kato, A. and Toda F. (2000). A decline in lower extremity lean body mass per body weight is characteristic of women with early phase osteoarthritis of the knee. J Rheumatol 27:2449-2454.

Toivanen, AT., Heliovaara, M., Impivaara, O., Arokoski, JP., Knekt, P., Lauren, H. and Kroger, H. (2010). Obesity, physically demanding work and traumatic knee injury are major risk factors for knee osteoarthritis - a population-based study with a follow-up of 22 years. Rheumatology 49(2):308-314. Van Saase, JL., Vandenbroucke, JP, van Romunde, LK. and Valkenburg HA. (1988). Osteoarthritis and obesity in the general population: a relationship calling for an explanation. J Rheumatol 15:1152-1158. Verbrugge, LM., Juarez, L. (2006). Profile of arthritis disability: II.Arthritis Care Res 55:102-11329. Vrhovac, B. (1997). Interna medicina. U Zlatko Domljan: Degenerativne bolesti zglobova i kralježnice. Zagreb 1495-1497.

Wang, Y. and Beydoun, MA. (2007). The obesity epidemic in the United States - gender, age, socioeconomic, racial/ethnic, and geographic characteristics: a systematic review and meta-regression analysis. Epidemiol Rev 29:6-28.

Wewers, M.E. and Lowe, N.K. (1990). A critical review of visual analogue scales in the measurement of clinical phenomena. Research in Nursing and Health 1990;13:227-236.

Wollfe, F. and Hawley, DJ. (1997). Measurement of the quality of life in rheumatic disorders using the EuroQol. Br J Rheumatol 36: 786- 793.

Yelin, E. (1998). The economics of osteoarthritis. In Osteoarthritis. Edited by Brandt K, Doherty M, Lohmander LS. New York, NY: Oxford University Press 23-30.

Zhang, W., Moskowitz, RW., Nuki, G., Abramson, S., Altman, RD., Arden, N., et al. (2008). OARSI recommendations for the management of hip and knee osteoarthritis, Part II: OARSI evidence-based, expert consensus guidelines. Osteoarthritis Cartilage 16:137-162. 